\title{
Marie de Flavigny, comtesse d'Agoult, Correspondance générale, t. IV: 1842-mai 1844 et suppléments: 1830-1841
}

\section{Lise Sabourin}

\section{(2) OpenEdition}

\section{Journals}

\section{Édition électronique}

URL : http://journals.openedition.org/studifrancesi/1571

DOI : 10.4000/studifrancesi.1571

ISSN : 2421-5856

Éditeur

Rosenberg \& Sellier

\section{Édition imprimée}

Date de publication : 1 novembre 2014

Pagination : 621

ISSN : 0039-2944

\section{Référence électronique}

Lise Sabourin, "Marie de Flavigny, comtesse d'Agoult, Correspondance générale, t. IV: 1842-mai 7844 et suppléments: 1830-1841 », Studi Francesi [En ligne], 174 (LVIII | III) | 2014, mis en ligne le 01 novembre 2014, consulté le 18 septembre 2020. URL : http://journals.openedition.org/studifrancesi/1571 ; DOI : https://doi.org/10.4000/studifrancesi.1571

Ce document a été généré automatiquement le 18 septembre 2020.

\section{cc) $(9)$}

Studi Francesi è distribuita con Licenza Creative Commons Attribuzione - Non commerciale - Non opere derivate 4.0 Internazionale. 


\title{
Marie de Flavigny, comtesse d'Agoult, Correspondance générale, $t$. IV: 1842-mai 1844 et suppléments: 1830-1841
}

\author{
Lise Sabourin
}

\section{RÉFÉRENCE}

MARIE DE FLAVIGNY, COMTESSE D’AGOULT, Correspondance générale, t. IV: 1842-mai 1844 et suppléments: 1830-1841, édition établie et annotée par Charles F. DUPÊCHEZ, Paris, Honoré Champion, 2012, pp. 863.

1 Charles F. Dupêchez poursuit l'édition de la Correspondance générale de Marie d'Agoult, enrichie d'agendas et de documents depuis 1830, avec introduction (pp. 9-13), l'utile index des correspondants, par avance enrichi des années à venir, et l'habituel index des noms de personnes. Ce tome IV atteint la période de 1842 à mai 1844 qui correspond à des années de lutte intérieure marquée par la décision progressive de rupture avec Liszt devant ses multiples liaisons ostentatoires au fil de sa tournée européenne à grand succès. C'est aussi le temps de mûrissement de ses projets d'écriture sous le pseudonyme de Daniel Stern, d'abord avec des critiques littéraires, musicales et artistiques dans «La Presse», puis avec la publication de la nouvelle Hervé et du roman Nélida.

2 Les relations familiales s'apaisent, par la reprise de contact avec sa fille Claire, avec les Flavigny aussi, quitte à devoir s'écarter, un peu contre son gré comme l'atteste l'amour qu'elle leur porte dans le «Journal d'un enfant», de Blandine, Daniel et Cosima Liszt. Marie d'Agoult renoue avec ses amis en littérature (Sainte-Beuve, Vigny, Sue, Hugo, Lamartine), mais aussi ses proches Lehmann et Ronchaud. Elle tient un salon très apprécié, y compris par les étrangers (voir la liste de ses hôtes, ses rendez-vous, des 
relevés de phrases échangées, dans les agendas de 1842-43): Bocage y lit la Lucrèce de Ponsard, Gutzkow et Herwegh diffusent son œuvre en Allemagne. Les «Lettres décrites d'une cellule», également présentes dans les suppléments de ce volume, permettent aussi de voir évoquer ses souvenirs d'enfance et ses trois amies - la baronne de Prulay, la marquise de Gabriac et George Sand - tandis que Louis de Viel-Castel fait le sien dans un «Portrait d'Arabelle».

3 Il s'agit donc d'une période de renaissance littéraire pour Marie d'Agoult, même si, toujours torturée par un sentiment de malédiction, au sein même de son engouement affectif pour son suicidaire neveu Léon Ehrman, elle reste hantée par le souvenir de Liszt et du destin de leurs trois enfants. 